\title{
Возможности использования мобильного обучения (m-learning) в процессе изучения английского языка для профессиональных целей (ESP)
}

\author{
Данилова В.А., ШихалкинаТ.Г., \\ Московский государственный университет имени Ломоносова, \\ Россия, 119991, г. Москва, Ленинские горы, д. 1 \\ E-mail: shikhalkina@inbox.ru
}

\begin{abstract}
Аннотация. Проанализированы различные методики преподавания английского языка для профессиональных целей (ESP) с использованием мобильных устройств, а также представлен широкий спектр заданий, разработанных авторами. Исследование основано на результатах опроса студентов 1 и 4 курсов Школы дизайна, Высшей школы экономки после применения методик мобильного обучения. Результаты исследования показывают, что большинство студентов первого курса предпочитают проходить обучение с использованием мобильных технологий. Отметим, что спектр заданий, предлагаемых в рамках мобильного обучения, включает в себя онлайн тестирование, задания на расширение словарного запаса и практику устной речи. Однако некоторые студенты Школы дизайна Высшей школы экономики настороженно воспринимают нововведения, так как считают традиционные методики преподавания английского языка более эффективными.
\end{abstract}

Ключевые слова: мобильное обучение, мобильные технологии (MALL), мобильные устройства, изучение английского языка для профессиональных целей, развитие языковых навыков

Для цитирования: Данилова В.А., Шихалкина Т.Г. 2020. Возможности использования мобильного обучения (m-Learning) в процессе изучения английского языка для профессиональных целей (ESP). Вопросы журналистики, педагогики, языкознания, 39 (2): 206-215. DOI 10.18413/2712-7451-2020-39-2-206-215

\section{M-learning in teaching english for specific purposes (ESP)}

\author{
Vasilisa A. Danilova, Tat'yana G. Shikhalkina \\ Lomonosov Moscow State University, \\ 1 Lenin's mountains, Moscow, 119991, Russia \\ E-mail: shikhalkina@inbox.ru
}

\begin{abstract}
Abstrache. The purpose of this article is to look into new opportunities of using mobile devices for teaching English to ESP students and develop an understanding of possible ways of incorporating these ideas into a classroom at the tertiary level. The research is based on prepared in advance questionnaire. Results of this study show that the majority of 1 st and 4th year students would like to be taught using new technologies but the offered tasks, which can be done in mobile learning, are limited to online tests and learning vocabulary and speaking. A number of 1st-year students of the Higher School of Economics, Russia are reluctant to any changes since they find the traditional way of teaching English more efficient.
\end{abstract}

Keywords: m-learning, MALL, mobile devices, ESP, language development.

For citation: Danilova V.A., Shikhalkina T.G. 2020. M-Learning in teaching english for specific purposes (ESP). Issues in Journalism, Education, Linguistics, 39 (2): 206-215 (in Russian). DOI 10.18413/2712-7451-2020-39-2-206-215 


\section{Введение}

Согласно данным Международного телекоммуникационного союза [Sanou, 2013] около 96 \% населения земного шара пользуется средствами мобильной связи. Наблюдается тенденция к использованию более одного мобильного телефона и планшета. Для большинства людей гаджеты являются не только средством осуществления телефонной и видеосвязи, но также средством социализации, работы и обучения в условиях реальной действительности. Термин «мобильное обучение» (м-обучение) - mobile learning (mlearning) - относится к использованию мобильных и портативных ИТ-устройств, таких как карманные компьютеры PDA (Personal Digital Assistants), мобильные телефоны, ноутбуки и планшетные ПК в преподавании и обучении [Crompton, Traxler, 2018.]. Мобильное обучение необходимо отличать от электронного дистанционного обучения, основанного на использовании компьютера, ноутбука и интернета. Его можно рассматривать как форму электронного дистанционного обучения с использованием мобильных устройств. Для студентов Высшей школы экономики (ВШЭ) подобная сетевая активность и участие в электронных курсах, отличных от английского, уже стали нормой. Студенты получают доступ к лекциям и семинарам по профильным предметам, однако использование мобильных технологий на занятиях по английскому языку являются редкостью.

В данной статье рассматриваются возможности мобильного обучения, технологии и отношение студентов, изучающих английский язык для профессиональных целей, к внедрению мобильного обучения в аудиторные занятия. Также авторы анализируют навыки обучения иностранному языку с помощью мобильных устройств и разрабатывают задания, которые могут применяться при обучении студентов бакалавриата.

\section{Мобильное обучение в XXI веке}

Преимущества мобильного обучения несомненны: обучение языку становится доступным миллионам людей, открываются возможностью самостоятельного выбора стратегии обучения. Встроенные словари, в которых можно найти перевод или объяснение неизвестного слова, а также его транскрипцию значительно облегчают процесс изучения иностранного языка. Мобильное обучение открывает новые перспективы для людей с ограниченными возможностями. Согласно М. Варшауэру [Warschauer, 2011], существует три основные проблемы, связанных с мобильным обучением, а именно: трансформация процессов преподавания и обучения, развитие навыков XXI века и продвижение социальной справедливости.

Внедрение новых цифровых технологий связано с возникновением новых программам обучения, общеобразовательных подходов и методик преподавания. По мере распространения личностно-ориентированного подхода в обучении преподаватель берет на себя структурирующую и направляющую функцию. Студенты становятся более свободными в выборе содержания и контекста. Появляется возможность размещать задания в информационных системах для получения обратной связи от других учащихся перед тем, как сдать выполненную работу преподавателю. Несмотря на то, что существует очень мало доказательств в пользу того, что мобильное обучение эффективнее традиционного обучения на аудиторных занятиях, несомненно то, что оно увеличивает автономность студента, при этом повышая вовлеченность учащихся в процесс обучения и коммуникации с преподавателем. Например, курс на платформе Coursera может быть дополнен одной консультацией в неделю для дополнительного обсуждения со студентами, что может оказаться очень удобным вариантом для тех, кто не может посещать аудиторные занятия в связи с частичной трудовой занятостью.

По мнению исследователей, навыки XXI века включают в себя такие личностные качества и компетенции, как «творческое мышление и инициативность, критическое мышление и решение задач, сотрудничество и умение работать в коллективе, автоном- 
ность и гибкость, образование на протяжении жизни, и все указанное выше в сочетании с компьютерной грамотностью» [Mishra, Kereluik, 2011; Dudeney et al., 2013]. Данные навыки имеют важное значение во всем мире, однако во многих странах, особенно в Азии, они дополняют существующие традиционные системы обучения. «Новые компетенции и навыки не только повышают шансы на самореализацию, но и обогащают личную и социальную жизнь» [Pegrum, 2014, p. 35].

Анализ потребностей является важнейшей стадией подготовки образовательных программ. В данном исследовании он был использован для выяснения, насколько студенты, изучающие английский язык для профессиональных целей, довольны существующими методиками обучения. Программа обучения английскому языку для студентов школы дизайна создавалась в соответствии с другими программами, основанными на развитии академических навыков, подготовке к сдаче экзамена IELTS и изучению языка в профессиональных целях. Специфика программы изучения английского языка для студентов Школы дизайна заключается в том, что начальный уровень знаний студентов довольно низок, так как для поступления от них не требовалась сдача ЕГЭ по английскому языку. Однако мотивация студентов к изучению языка является высокой. В данных обстоятельствах от преподавателя английского языка требуется высокое мастерство, чтобы сделать занятия по английскому интересными и запоминающимися.

\section{Сбор и анализ данных}

Для анализа потребностей студентов в изучении английского языка с использованием новых технологий были опрошены 52 студента первого курса и 22 студента четвертого курса Школы дизайна ВШЭ. Студентам предлагалось ответить на вопросы, отличающиеся по содержанию, так как первая группа опрашиваемых только приступала к курсу изучения английского языка, а вторая уже заканчивала данный курс. Обе группы студентов никогда не использовали мобильные устройства для изучения английского языка. Студенты ответили на следующие вопросы:

Для 1 курса:

1. Хотели бы вы использовать мобильные устройства на занятиях по английскому языку? Почему?

2. Какие навыки вы бы могли совершенствовать с помощью мобильных технологий?

3. Какие способы изучения английского языка могли бы использоваться для развития необходимых навыков?

Для 4 курса:

1. Сожалеете ли вы о том, что при обучении английскому языку мобильные устройства не использовались? Почему?

2. Какие языковые навыки вы бы могли совершенствовать с использованием мобильных технологий?

3. Какие способы изучения английского языка могли бы использоваться для развития необходимых навыков?

Результаты исследования показали, что из 52 опрошенных студентов 1 курса 39 выразили желание использовать мобильные технологии и устройства в процессе обучения. В качестве основных аргументов студенты называли возможность расширения словарного запаса, совершенствования навыков аудирования и говорения, быстрого развития языковых навыков, а также отметили, что процесс обучения в целом становится более удобным и современным. Студенты также могут отвечать на вопросы онлайн и делать пометки на своих устройствах, занятия становятся более занимательными.

Тем не менее, 13 студентов высказались против мобильного обучения. Они отметили, что используют мобильные устройства в повседневной жизни и согласились с тем, 
что занятия английским языком уже являются интерактивными. При этом студенты сообщили, что работать с телефонами недостаточно удобно и чтение с экрана менее привлекательно, чем чтение книги или чтение с листа бумаги. Студенты также утверждали, что использование устройств является отвлекающим фактором и мешает концентрации на занятии.

Отвечая на 2 вопрос, студенты предположили, что использование мобильных устройств может содействовать развитию навыков письма, совершенствованию навыков презентаций, расширению словарного запаса и пониманию грамматики, а также повышает эффективность поиска информации, развивает скорость мышления и в целом увеличивает готовность студента к самообразованию. В ответах на 3 вопрос студентами было предложено решение тестов и выполнение письменных работ, просмотр фильмов и участие в дискуссии, скачивание материалов и использование таких инструментов, как Socrative.org и Siri. Результаты опроса представлены на рис. 1.

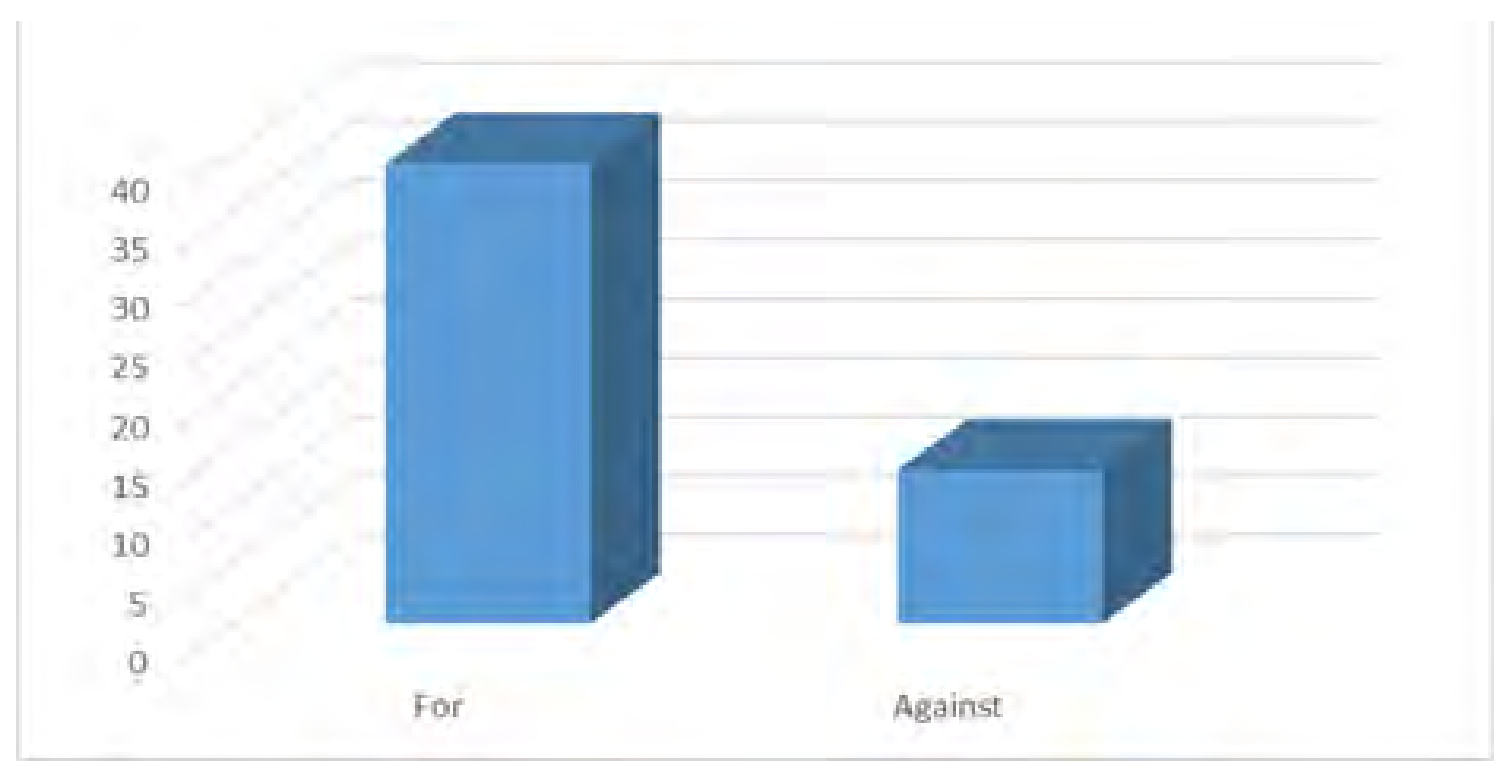

Рис. 1. Результаты опроса студентов 1 курса

Fig. 1. Resultsof 1styearstudents

Из 22 опрошенных студентов 4 курса только 7 выразили сожаление по поводу того, что во время обучения они не пользовались мобильными устройствами, которые могли бы привнести интерактивный элемент в занятие, сделать процесс обучения более интересным, предоставить быстрый доступ в интернет, облегчить процесс изучения материала и предоставить больше возможностей для личной практики. При этом 15 студентов ответили, что не имеют представления о том, как мобильные устройства могли бы применяться на занятиях по английскому языку. По их мнению, традиционное обучение помогает развивать все необходимые навыки, занятия английским вызывали интерес, были одновременно познавательными и увлекательными без использования мобильных устройств и с применением распечатанных материалов и учебников.

Отвечая на 2 вопрос, студенты предположили, что мобильные устройства могли бы содействовать развитию воображения и визуальной памяти, расширению словарного запаса, совершенствованию грамматических и разговорных навыков. В ответе на 3 вопрос большинством студентов было предложено применение мобильных устройств для участия в интерактивных играх, решения письменных тестов, просмотра фильмов с субтитрами и поиска учебников с современным подходом к процессу обучения английскому языку. 
Помимо этого, мобильные устройства открывают доступ к различным игровым технологиям, методикам расширения словарного запаса (Lingualeo), мобильным приложениям, Skype, Ehatrulet для выполнения проектных творческих заданий. Результаты опроса представлены на рис. 2.

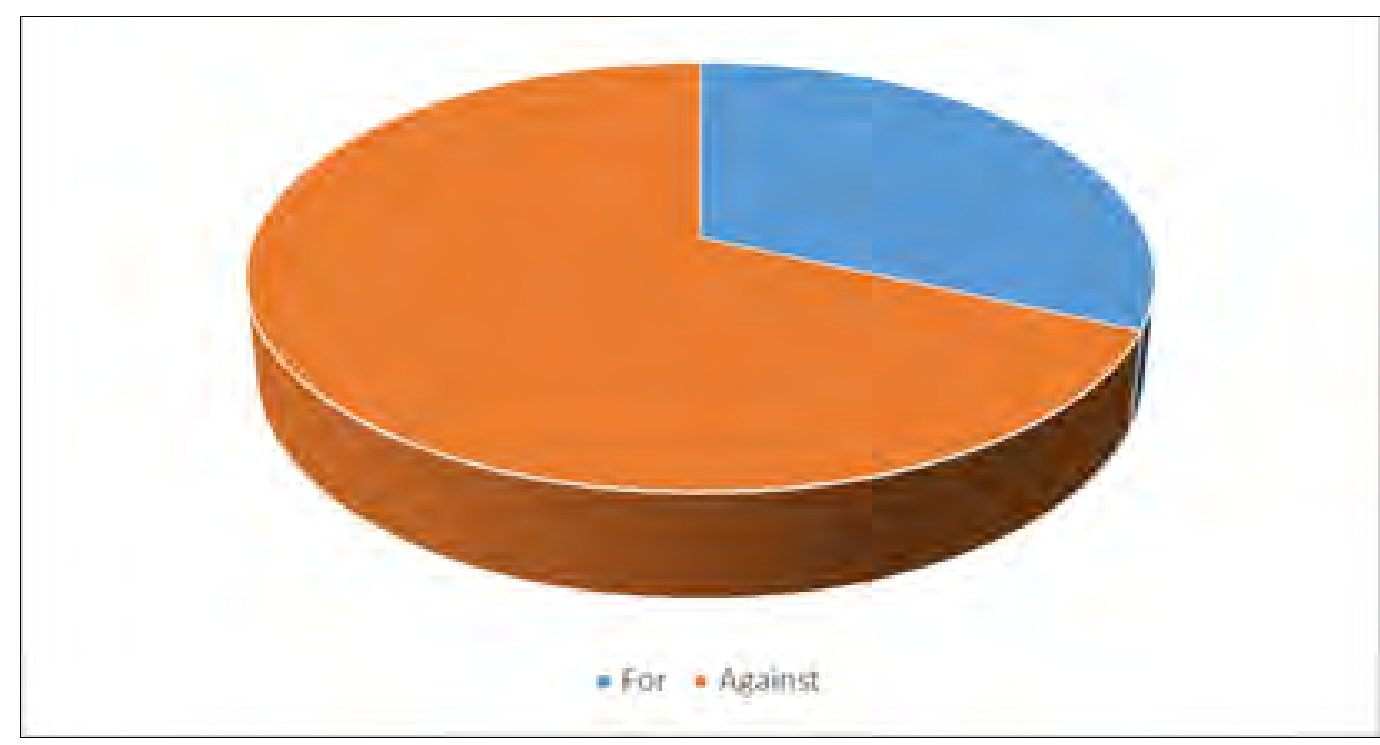

Рис. 2. Результаты опроса студентов 4 курса

Fig. 2. Resultsof 4thyearstudents

\section{Обучение чтению и письму}

Мобильные устройства предоставляют множество возможностей для обучения чтению. Устройства (включая электронные книги) помогают студентам освоить новую лексику, предоставляя ссылки на словари, правила грамматики, задания до и после прочтения текста. Например, персонифицированная система интеллектуального мобильного обучения (PIMS), разработанная для изучения английского языка в Тайване, предлагает опцию по оценке уровня навыков чтения обучающегося и в соответствии с результатами предлагает к прочтению новостные статьи, снабженные переводом на китайский [Chen, Hsu, 2008]. Необходимо упомянуть и разнообразие образовательных приложений, которые позволяют студентам увеличивать их словарный запас, предлагая перевод и аудио запись с произношением каждого отдельного слова. Например, Ortsbo - новое приложение, созданное фирмой из Торонто, для перевода слов в электронных книгах, призванное нивелировать языковой барьер. В приложение встроена опция произношения выделенного слова в аудио формате [Bicen et al., 2015].

В ВШЭ преподаватели английского языка используют онлайн-платформу Google Classroom, которая позволяет внедрять в занятия интерактивное чтение для работы над совершенствованием навыков понимания текста и скорости прочтения, используя инструмент Read \& Write.

B целях развития навыков письма, мобильное обучение предлагает возможность поиска ошибок, проверку орфографии и ударений. Студенты также могут сочинять короткие тексты на различные ситуации, загружать картинки и детализированные описания. Одним из самых популярных приложений для улучшения навыков письма является Grammarly, которое в режиме онлайн выверяет текст, проверяет грамматику и помогает избавиться от ошибок, осуществляя контроль орфографии [EducationalTechnology.., 2018]. 


\section{Обучение аудированию и говорению}

Онлайн задания по аудированиюможно легко скачать в виде радио подкастов или книг с аудиоприложением. The Learn English Podcast - приложение, созданное Британским советом, в котором для прослушивания предлагаются увлекательные интервью на темы из реальной жизни («знаменитости», «еда», и т.д.). Аудио запись каждого эпизода сопровождается субтитрами и вопросами для самопроверки. Приложение English Listening Practice - World Talks целиком сфокусировано на обучении английскому языку через прослушивание. В нем загружено более 1100 интервью. Слушателям предлагается запись ответов шести разных людей на один и тот же вопрос, что позволяет познакомиться с различными диалектами.

Такие онлайн платформы, как Edmodo, Moodle, Canvas, Google classroom дают преподавателям ВШЭ возможность использовать адаптированные онлайн материалы из различных интернет-источников (TED talks, академическое аудирование для IELTS, и т.д.) для создания тестов по аудированию.

Задания наговорение включают работу над произношением, отработку звуков и даже запись собственного произношения для сравнения с примером произношения носителя языка, что является очень важным для таких языков, как китайский [O’Brien, 2006], a также для работы над интонацией в различных языках [Iftakhar, 2016.]. Для развития навыков говорения успешно применяется целый ряд мобильных приложений, одним из которых является, English Listening and Speaking. Приложение включает тысячи аудиозаписей бесед на английском языке с транскрипцией. Другим примером может послужить Speak English Fluently, приложение, созданное, чтобы поддержать пользователей в изучении разговорного английского с американским акцентом.

В ВШЭ на занятиях по английскому языку особенно полезным является Fluency Tutor. Это приложение на базе интернет технологий, используемое в рамках Google classroom, которое предоставляет студентам возможность практиковать и записывать чтение вслух и получать оценку.

\section{Обучение грамматике и расширение словарного запаса}

Мобильные приложения являются наиболее распространенным способом расширения словарного запаса [Pegrum, 2014, p.134]. Это продемонстрировано Британским советом в приложении Nokia Life, которое создано в расчете на три уровня владения языком (легкий, средний и сложный). Множество приложений предоставляют возможность расширения словарного запаса через игру. Например, Knudge предлагает множество упражнений и игр, которые помогут в изучении новых слов и расширении словарного запаса на английском языке. Quizlet, созданное в качестве тестовой игры, используется с дидактическими карточками, которые помогают проверять изученный словарный запас. Также доступна аудио-транскрипция для работы над произношением [Iftakhar, 2016, p. 12].

Еще одним примером является Bookwidgets, приложение, которое можно интегрировать в любую систему управления обучением (LMS), включая систему ВШЭ. В приложение включены шаблоны для вопросов и игр (дидактических карточек, кроссвордов, и т.д.), которые автоматически оцениваются и визуально являются более привлекательными для студентов, чем стандартные рабочие материалы на бумаге [Menon, 2019, p. 168].

Подход к изучению грамматикиво многом схож с подходом к закреплению словарного материала в упражнениях MALL (обучение языку с помощью мобильных технологий). Это демонстрирует проект MASELTOV (Mobile Assistance for Social Inclusion and Empowerment of Immigrants with Persuasive Learning Technologies and Social Network Services - «Мобильное приложение для социальной интеграции и расширения возможностей иммигрантов с помощью мотивирующих технологий обучения и социальных сетей»), в котором грамматике отведено такое же место, как и словарному запасу и другим аспектам языка. 
Другим примером является приложение Learn English Grammar, которое предлагает практический способ изучение грамматики английского языка. Приложение создано для обучающихся всех уровней, каждый уровень включает более 600 грамматических упражнений, разделенных на 25 тем, с целью систематического изучения грамматики английского языка.

Благодаря технологии Text-to-Speech (прослушивание прочитанного текста) и Book Widgets студенты ВШЭ получают мгновенный отклик на выполненное задание, а также могут просматривать результаты работы и сравнивать свои ответы с правильными вариантами.

\section{Примеры заданий для мобильного обучения}

В целях создания различных видов интерактивных заданий для студентов преподаватели могут использовать целый ряд систем управления обучением (LMS) и онлайн сервисов. Преподавателями ВШЭ были предложены несколько решений для мобильного обучения с использованием Google classroom (LMS) и приложения Bookwidgets.

Упражнения делятся на 4 категории: лексические, грамматические, аудирование и просмотр видео, чтение и письмо.

Лексика

1) Дидактические карточки (flash cards) - это словесные игры, которые являются прекрасным способом изучить новые слова и протестировать полученные знания. Преподаватели могут использовать их в классе для проверки знаний студентов.

2) Кроссворд - это задание, составленное из списка слов и их дефиниций. Задание может быть использовано для проверки усвоенной лексики.

3) «Виселица» (hangman) - классическая игра для улучшения орфографии и запоминания слов.

4) «Найди слово» (word search) - это головоломка, которая помогает запомнить новые слова и отработать их употребление.

Грамматика

5) Таблица - упражнение на заполнение таблицы в основном используется для многократной тренировки запоминания грамматических форм, например, неправильных глаголов, времен, и т.д.

6) Заполнение пропусков (gap filling) - упражнение, в котором учащиеся заполняют пропуски, является особенно полезным при изучении грамматики английского языка.

7) «Перенести и вставить» (Drag and drop) - упражнение на определение категории и отбор, нацеленное на повторение грамматических форм.

Аудирование и просмотр видео

8) Мультимедиа - это видеоматериал, который встроен прямо в курс, что позволяет смотреть фильмы с канала HD YouTube из интернета, не выходя из iBook, а также отвечать на вопросы после просмотра. На занятиях могут быть использованы как обучающие видео, так и классические.

Чтение и письмо

9) Вопросы по тексту - это тип заданий, включающий материал для прочтения и последующий список вопросов. Подразумевается, что на каждый вопрос существует только один ответ. Упражнение может использоваться с целью отработки лексического материала и перевода текста. Многострочный текстовый вопрос позволяет давать любые письменные задания, такие как эссе, статьи, предложения, письма и т.д.

10) Вопрос с множественным выбором (Multiple choice) - форма контрольных вопросов, при которой отвечающий должен выбрать только один правильный ответ из списка вариантов.

Все упражнения для мобильного обучения могут быть отправлены студентам с помощью ссылки (схожей со ссылкой на видео в YouTube), ею также можно делиться через 
систему управления обучением (LMS) или социальные сети. Студенты, получившие ссылку, смогут выполнить задание вне зависимости от типа используемого устройства. После выполнения студентом задания или теста преподаватель может давать обратную связь.

Примеры заданий показаны на рис. 3 и 4.

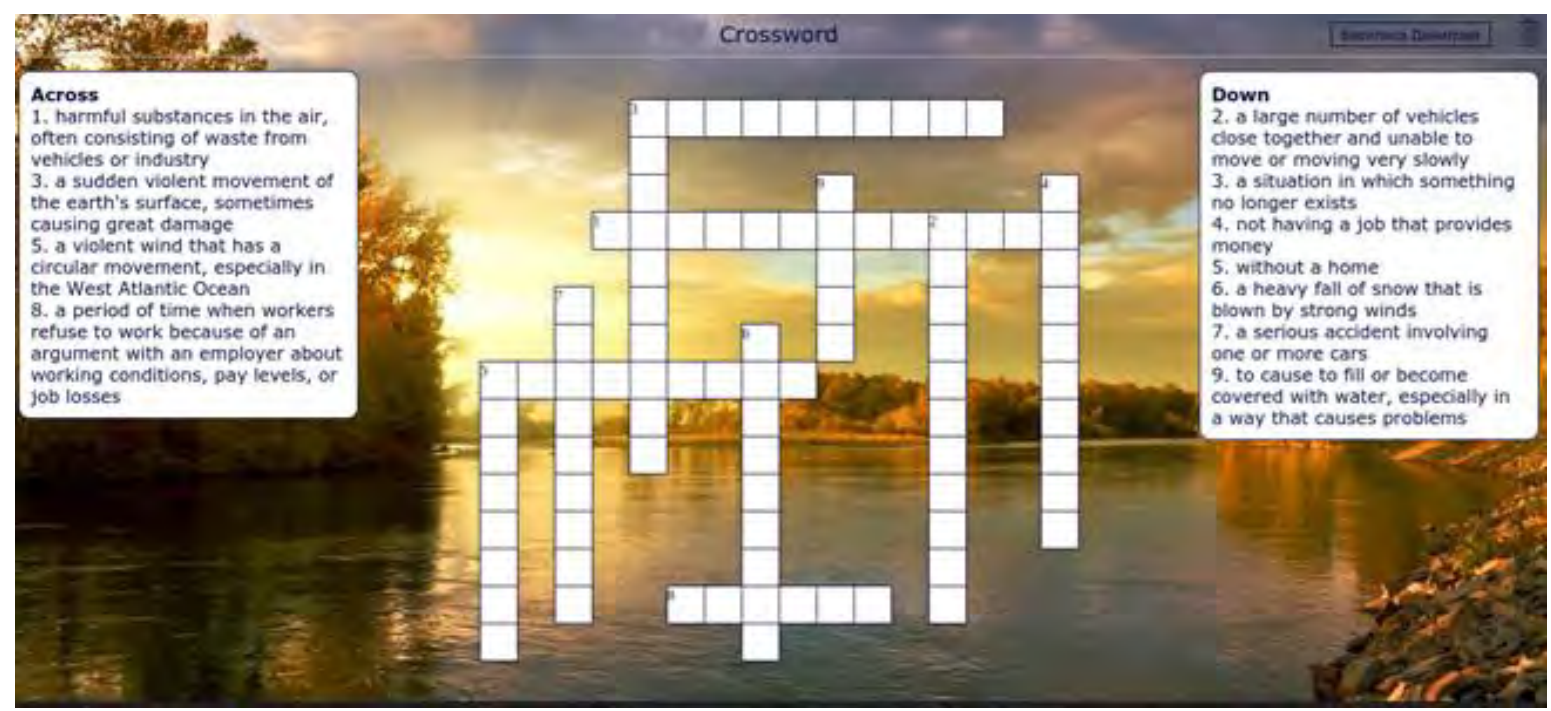

Рис. 3. Кроссворд

Fig. 3. Crossword Puzzle

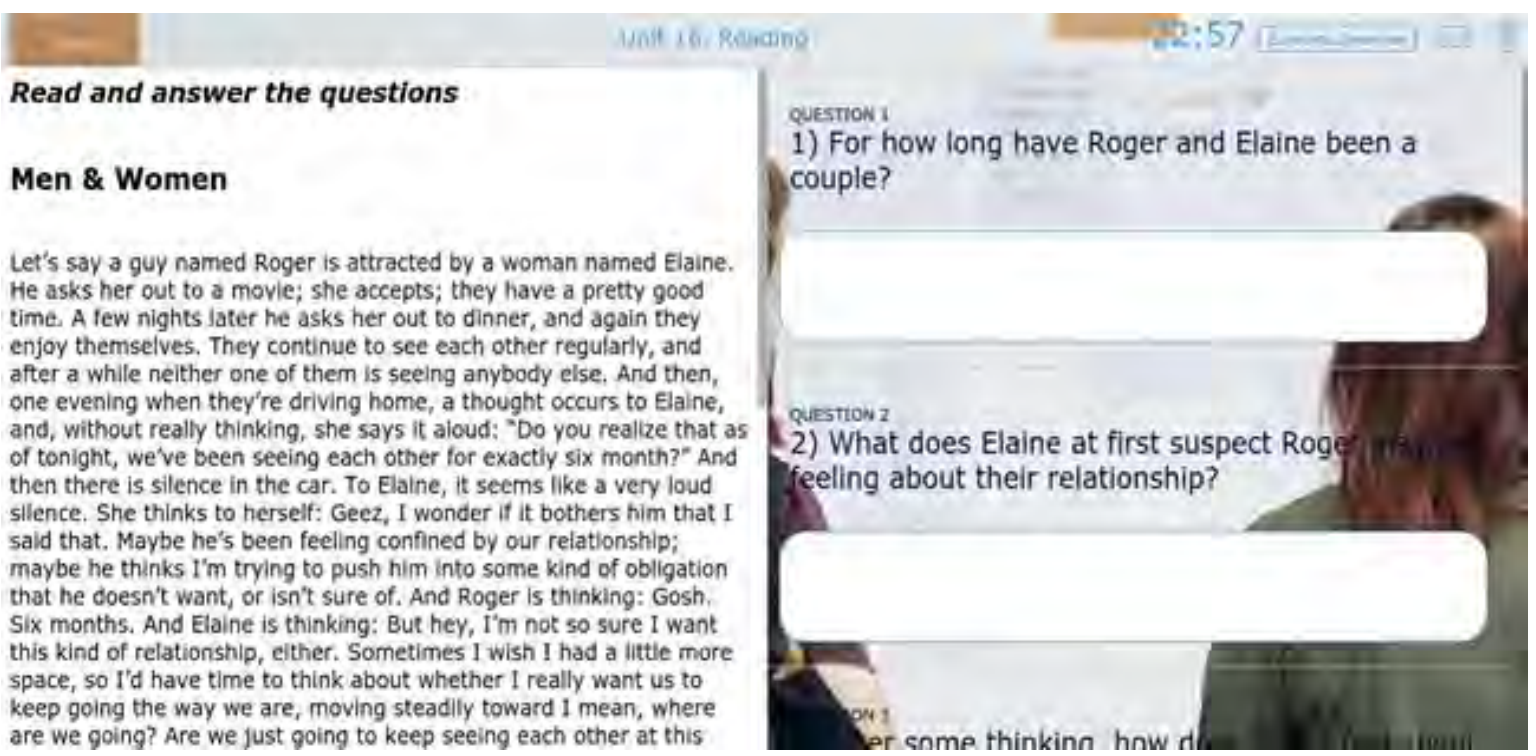

Рис. 4. Вопросы к тексту

Fig. 4. Questions to the text

\section{Мнения студентов и анализ}

Студентам 1 курса Школы дизайна (ВШЭ) предложили выполнить интерактивные задания и оценить их. В опросе участвовали 63 студента. Им были заданы следующие вопросы:

1. Какое упражнение вам понравилось больше? Почему?

2. Какое упражнение вам понравилось меньше всего? Почему? 
Студенты могли выбрать одно или несколько упражнений или пропустить вопрос.

Согласно исследованию, студенты высоко оценили мультимедийные упражнения и дидактические карточки, при этом 56 из 58 (мультимедия) и 55 из 56 (дидактические карточки) студентов сообщили, что им было интересно выполнять эти задания в аудитории или дома. Они также отметили, что использование видео-материала имеет высокий образовательный потенциал и способствует улучшению навыков восприятия английской речи. Дидактические карточки облегчают процесс изучения новых слов, добавляя визуальную составляющую. Напротив, упражнение на заполнение пропусков получило самую низкую оценку: 21 из 39 студентов проголосовали против данного метода изучения грамматики, назвав его слишком традиционным и не вызывающим интерес. Другие упражнения в основном получили высокую оценку студентов. В целом задания для мобильного обучения были признаны увлекательным методом изучения английского языка. Результаты представлены на рис. 5.

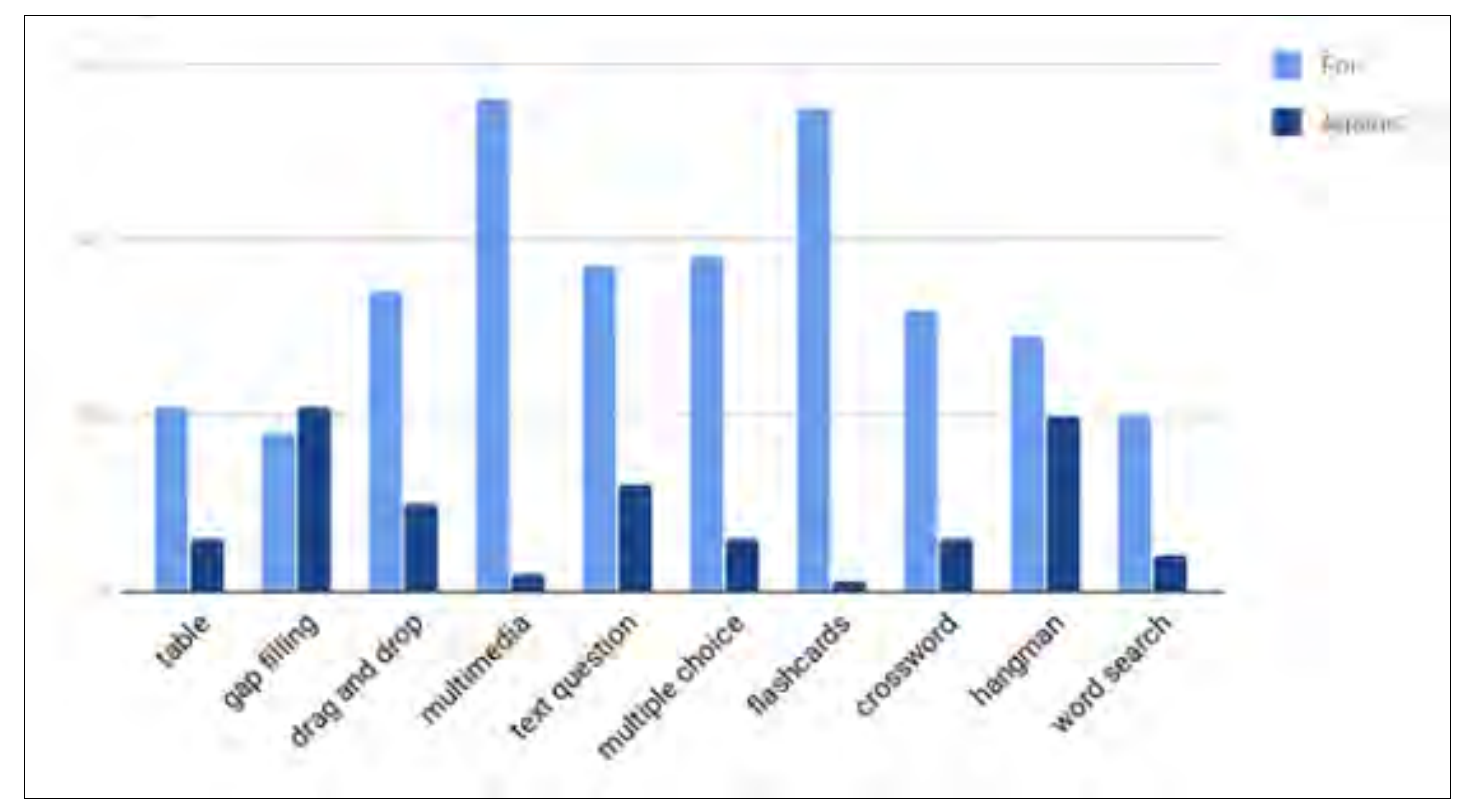

Рисунок 5. Результатыопросастудентов 1 курса

Figure 5. Results of 1 st year students

\section{Заключение}

В настоящее время существует большой интерес к использованию мобильных технологий в образовании, но они еще недостаточно распространены на уровне высшего образования. Студенты ВШЭ выбирают мобильное обучение, находя его более полезным и увлекательным. Исследование показывает, что студентам нравится использование мобильных технологий как во время аудиторной работы, так и в качестве домашнего задания. Мультимедийные задания и дидактические карточки были наиболее высоко оценены студентами, а заполнение пропусков оказалось наименее популярным заданием.

Мобильное обучение делает свои первые шаги в университетском образовании, и повышение квалификации преподавателей с учетом этой тенденции становится острой необходимостью. Преподаватели, имеющие навыки в использовании цифровых технологий, могут оказать студентам профессиональную поддержку в мобильном обучении, что значительно увеличит эффективность занятий английским языком.

В дальнейшем планируется анализ эффективности мобильного обучения, а результаты данного исследования могут быть использованы с целью развития навыков XXI века. 


\section{Список источников}

1. Mishra P., Kereluik K. 2011. What 21st Century Learning? A review and a synthesis. In: M. Koehler \& P. Mishra, Proceedings of SITE 2011--Society for Information Technology \& Teacher Education International Conference Mar 07, 2011. Nashville, Tennessee, USA, Association for the Advancement of Computing in Education (AACE): 3301-3312.

2. NCTE (National Council of Teachers of English) [USA]. 2005. Position Statement on Multimodal Literacies. Availableat: http://www.ncte.org/positions/statements/multimodalliteracies (accessed: 08.02.2020).

3. Educational Technology and Mobile Learning. A resource of educational web tools and mobile apps for teachers and educators. 2018. Available at: https://www.educatorstechnology.com/ (accessed: 08.02.2020)

4. Sanou B. 2013.The world in 2013: ICT Facts and Figures. Geneva,ITU. Availableat: https: //www.itu.int/en/ITU-D/Statistics/Documents/facts/ICTFactsFigures2013-e.pdf (accessed: 18.02.2020).

\section{References}

1. Crompton H., Traxler, J. 2018. Mobile Learning and Higher Education. NewYork, Routledge, $222 \mathrm{p}$.

2. Warschauer M. 2011. Learning in the Cloud: How (and Why) to Transform Schools with Digital Media. New York, Teachers College Press, $144 \mathrm{p}$.

3. Dudeney G., Hockly N.L., Pegrum M. 2013. Digital Literacies: Research and Resources in Language Teaching. Pearson Education Limited, United Kingdom. Available at: https://researchrepository.uwa.edu.au/en/publications/digital-literacies-research-and-resources-in-language-teaching (accessed: 08.02.2020)

4. Pegrum M. 2014. Mobile Learning. Languages, Literacies and Cultures. New York, Palgrave Macmillan, $257 \mathrm{p}$.

5. Chen C.-M., Hsu S.-H. 2008. Personalized intelligent mobile learning system for supporting effective English learning. Educational Technology \& Society, 11(3): 153-180.

6. Bicen H., Sadikoglu S. \& Sadikoglu, G. 2015. The impact of social networks on undergraduate students learning foreign language. Procedia, Social and Behavioral Sciences, 186, 1045-1049.

7. Chun D.M., Jiang Y., Avila N. 2013. Visualisation of tone for learning Mandarin Chinese. In: J. Levis $\&$ K. LeVelle, Proceedings of the $4^{\text {th }}$ Pronunciation in Second Language Learning and Teaching Conference, August 2012. Ames, IA, Iowa State University: 77-89.

8. O'Brien M.G. 2006. Teaching pronunciation and intonation with computer technology. In: L. Ducate and N. Arnold, Calling on CALL: From Theory and Research to New Directions in Foreign Language Teaching. San Marcos, Texas, Computer Assisted Language Instruction Consortium: 127-148.

9. Iftakhar S. 2016. Google Classroom: What Works and How? Journal of Education and Social Sciences, Vol. 3, (Feb): 12-13.

10.Menon S. 2019. Designing Online Materials for Blended Learning: Optimising on BookWidgets, International Journal of Linguistics, Literature and Translation (IJLLT), Vol. 2 (May): 167-168.

\section{ИНФОРМАЦИЯ ОБ АВТОРАХ}

Данилова Василиса Андреевна, аспирант Московского государственного университета им. М.В. Ломоносова, г. Москва, Россия

Шихалкина Татьяна Григорьевна, аспирант Московского государственного университета им. М.В. Ломоносова, г. Москва, Россия

\section{INFORMATION ABOUT THE AUTHORS}

Vasilisa A. Danilova, graduate student of Moscow State University. M.V. Lomonosov, Moscow, Russia

Tat'yana G. Shikhalkina, graduate student o Moscow State University. M.V. Lomonosov, Moscow, Russia 